\title{
ROTA DE ARTE RUPESTRE DO NOROESTE PORTUGUÊS. UM PROJETO PARA O DESENVOLVIMENTO DE UMA PRÁTICA TURÍSTICA SUSTENTÁVEL
}

Ana M. S. BETTEMCOURT ${ }^{1}$, Hugo A. SAMPAIO ${ }^{2}$, Daniela CARDOSO ${ }^{3}$, Sofia SÁ $^{4}$ e Alda ROdRIGUES ${ }^{5}$

Instituto de Ciências Sociais da Universidade do Minho, Braga, Portugal; Laboratório de Paisagens, Património e Território (Lab2 PT). E-mail: anabett@uaum.uminho.pt ${ }^{1}$

Instituto Politécnico do Cávado e do Ave, Barcelos, Portugal; Lab2 PT. E-mail: hugoaluai@gmail.com²

Sociedade Martins Sarmento; Centro de Geologia da Universidade de Coimbra; Lab2 PT. E-mail: danyrest@gmail.com ${ }^{3}$ Mestre em Património e Turismo Cultural. E-mail: sofiacarneirosa@gmail.com ${ }^{4}$ Lab2 PT. E-mail: aldacrodrigues@gmail.com ${ }^{5}$

Submetido 15/12/2016 - Aceito 11/01/2017

\section{RESUMO}

A Rota de Arte Rupestre do Noroeste é um projeto que pretende explorar as potencialidades da arte rupestre do NW de Portugal enquanto recurso passível de desenvolvimento de uma prática turística sustentável. O NW português é uma área rica em arte rupestre de ar livre de cronologia pós-paleolítica, em especial do estilo designado de Arte Atlântica, específico da área. Além do seu inegável valor científico, o caráter estratégico deste recurso patrimonial deveria integrar programas de desenvolvimento e de organização do território.

Para que tal se concretize há que colmatar carências ao nível da investigação, tais como a compilação e sistematização dos dados que promovam o avanço do conhecimento científico e, simultaneamente, propiciem discursos atrativos para o público em geral.
O projeto tenciona aprofundar a investigação da arte rupestre segundo perspetivas arqueológicas e antropológicas, contribuir para salvaguardar este património arqueológico e promover a sua valorização na fachada ocidental no NW de Portugal, por forma a que se possa criar o produto turístico sustentável "Rota de Arte Rupestre do Noroeste". Visa, ainda, rentabilizar o património "intangível" ligado a estes recursos, os recursos humanos das parcerias envolvidas no projeto e incrementar o desenvolvimento sustentável do território abordado.

Serão divulgadas as ações já materializadas e/ou em vias de materialização, bem como os resultados atingidos para diferentes áreas do NW.

PALAVRAS-CHAVE: gravuras rupestres, produto turístico, desenvolvimento regional, sustentabilidade.

\section{NORTHWEST OF PORTUGUESE ROCK ART ROUTE. A PROJECT TO DEVELOP A SUSTAINABLE TOURISCTIC PRACTICE}

\begin{abstract}
The project "Northwest Rock Art Route" aims to explore Portuguese NW rock art resource potentialities as capable of increase sustainable development of touristic practices.

The Portuguese NW is rich in open-air post-Palaeolithic rock art, especially from the designated Atlantic Art, specific from the area. Along with its scientific value, its strategic character should integrate programs of territory development and organization.

In order to achieve that, some scientific needs have to be overcome, like data compilation and systematization, promoting scientific knowledge and allowing attractive discourses to general public.
\end{abstract}

The project intends to deepen rock art research according to archaeological and anthropological perspectives, to contribute to its protection, and to promote its valorisation in the western façade of Portuguese NW. Ultimately, it pretends to create the sustainable touristic product "Northwest Rock Art Route". It also aims to transform its related "intangible" heritage in something profitable, so as the involved project partnerships human resources, and increase the sustainable development of the addressed area.

The materialized and/or in process of materialization actions will be presented, so as the different achieved results from each NW area.

KEYWORDS: rock art engravings, touristic product, regional development, sustainability. 


\section{INTRODUÇÃO}

As rotas são das práticas turísticas mais procuradas na vertente do Turismo Cultural, pois oferecem ao visitante temáticas de interesse ao mesmo tempo que facilitam o acesso a outros produtos locais pré-existentes (Maia e Baptista, 2011), como, por exemplo, a gastronomia e vinhos, o artesanato, o património arquitetónico e paisagístico, entre outros.

São, portanto, geradoras de valor económico a diversos níveis, pois geram oportunidades de negócios e promovem a criação de emprego, e proporcionam aos visitantes a experienciação de diferentes tipos de produtos, contribuindo para melhorar a qualidade de vida da população local.

Mas as rotas culturais também proporcionam aos visitantes uma interação direta com a cultura local e possibilitam à população residente (em face de perder a sua memória identitária) a melhor compreensão do espaço onde vivem, a identificação e proximidade com o passado e o consequente respeito e orgulho pelo seu património, sendo, pois de inegável valor social (Maia et al., 2013).

A Rota de Arte Rupestre do Noroeste é um projeto de uma rota turístico-cultural que pretende explorar as potencialidades da arte rupestre gravada no Noroeste de Portugal, enquanto recurso passível de desenvolvimento regional e de uma prática turística sustentável.

Segundo o site da Unesco a arte rupestre, pintada ou gravada "...is a clear and lasting evidence of the transmission of human thoughts and beliefs through art and graphic representations. It functions as a repository of memory, enabling each culture to speak about themselves and their origins in all geographical settings" (http://whc.unesco.org/en/eur-na/).

Em termos mundiais, existem diversos sítios de arte rupestre classificados como património da Humanidade de que são exemplo, na Europa, a Arte do Vale do Côa, em Portugal; a Arte da Bacia Mediterrânica, em Espanha; a Gruta de Altamira e a Arte Paleolítica das Grutas do Norte de Espanha; a Arte Rupestre do Vale da Vézère, em França; Valcamónica, em Itália; a Arte do rio Madara, na Bulgária; a Arte Rupestre de Alta, na Noruega; a Arte Rupestre de Tanum, na Suécia e a Arte Rupestre de Gobustan, no Azerbeijão (S/a, 2009). Muitos destes locais têm sido explorados como produtos turísticos, o que é importante para valorizar a sua conservação, apesar da vulnerabilidade deste património. Por este motivo a valorização deste recurso exige, naturalmente, um quadro de gestão eficaz, sob pena da sua rápida degradação (Duval e Smith, 2013).

Por este motivo, a rota proposta, que abarca um vasto território, desde o vale do Vouga ao vale do Minho (Figura 1), deve ser desenvolvida em diversos contextos, gerida por uma entidade que agregue todo o território ou, em conjunto, por várias entidades que representem os diferentes territórios abarcados. Deve, pois, ser entendida como um produto de cooperação inter-regional.

Neste sentido, a rota de Arte Rupestre do Noroeste deverá ser objeto de uma política de conservação comum, de modo a que todos os sítios selecionados para integração na rota sejam objeto de ações de limpeza, conservação e manutenção similares; de uma política de 
interpretação comum, para que todos os sítios selecionados para integração na rota sejam objeto de interpretação similar (nomeadamente, conteúdos cientificamente validados e conteúdos adaptados a diferentes tipos de público); de uma política de comunicação comum (imagem), em concreto no que se refere ao espaço/espaços de informação e recepção dos públicos (este poderá ser único, ocupando uma área central ou de entrada na rota, ou composto por diversos espaços distribuídos ao longo dela, em função da sua área geográfica); de uma política comum relativa aos instrumentos de comunicação e divulgação in loco (como sinalética de direção, informação e interpretação); de uma política comum relativa aos instrumentos de comunicação e divulgação impressa (mapas/livros e folhetos) ou mesmo digital (sítio online e aplicações móveis).

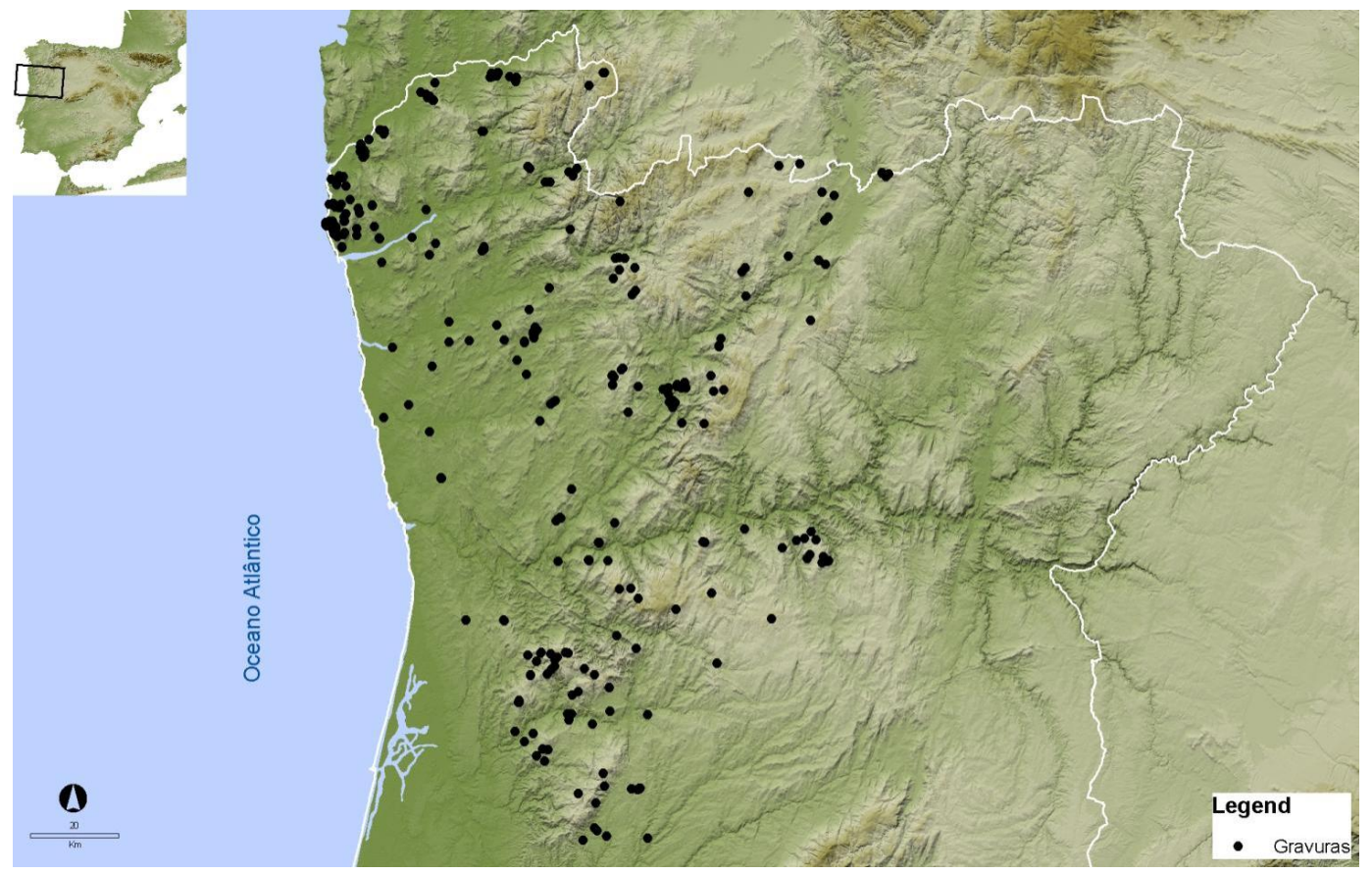

Figura 1. Área de distribuição do projeto Rota de Arte Rupestre do Noroeste Português e sua localização na

Península Ibérica (em cima, à esquerda).

\section{A ROTA DE ARTE RUPESTRE: RECURSOS E SUSTENTABILIDADE}

O Noroeste é uma área muito rica em sítios de arte rupestre de ar livre, nomeadamente o que se designa por Arte Atlântica, um estilo único nesta área geográfica e na Galiza. São manifestações culturais que para alguns autores apresentam diferentes fases que datam da Préhistória Recente, entre o 4ㅇ e o 1일ión a.C., ou seja, que foram realizadas entre 6 a 3 mil anos antes do presente (como por exemplo Alves, 2003); Santos-Estévez, 2012). Incluem simbologia abstrata (covinhas, círculos ou semicírculos concêntricos, círculos ou ovais preenchidas por nuvens de pontos, espirais, labirintiformes), por vezes ligados por meandros, e simbologia naturalista (armas, excelentes indicadores cronológicos, zoomorfos, representando diferentes espécies animais, entre eles, cavalos, por vezes montados, e antropomorfos).

Se muitos afloramentos contêm poucas gravuras, alguns há que podem considerar-se lugares cerimoniais de excelência pela profusão de motivos que apresentam, resultantes, 
provavelmente, da frequência cíclica por parte dos visitantes, por vezes, durante milhares de anos e que aí foram adicionando ou sobrepondo novos motivos aos pré-existentes (Figura 2).

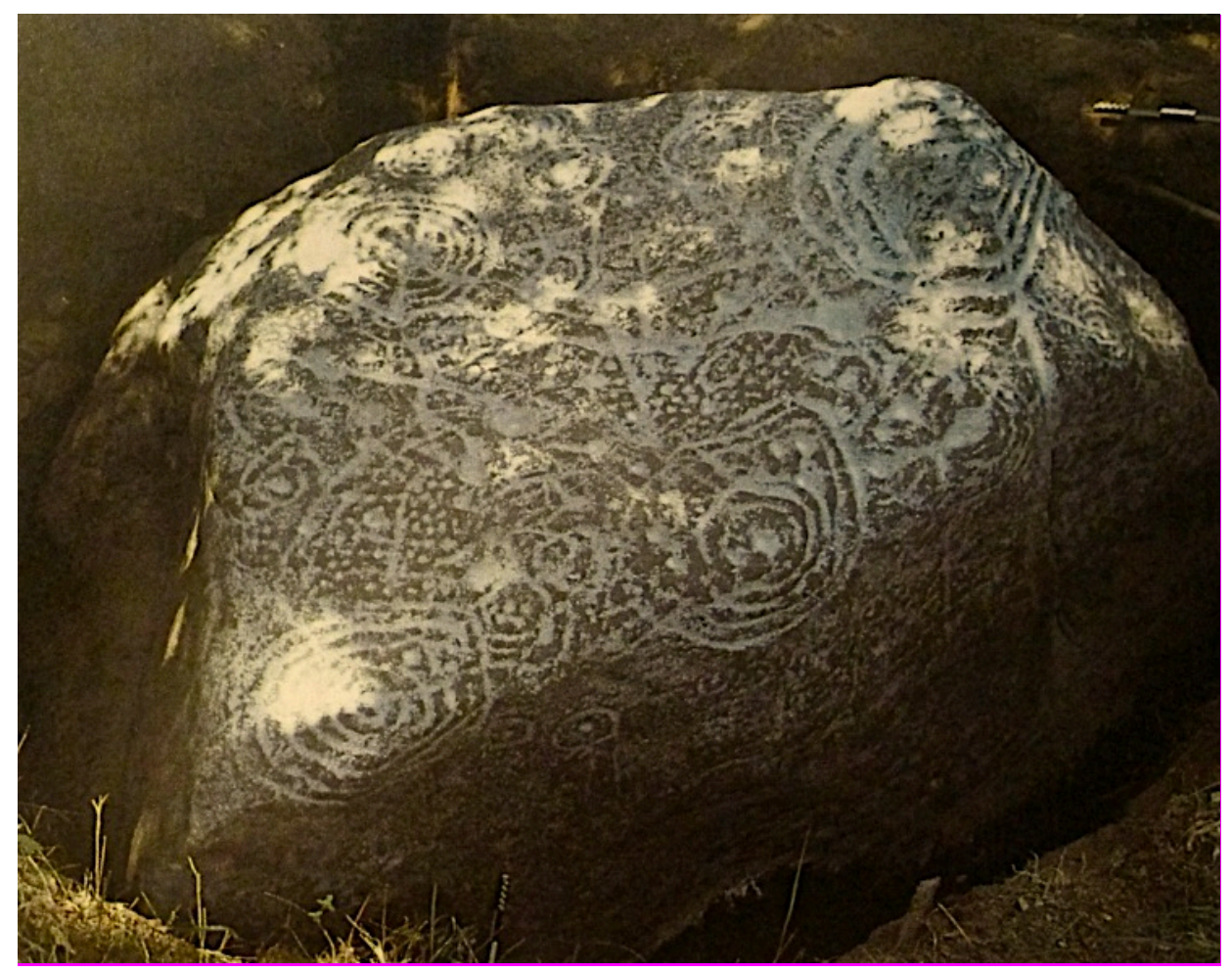

Figura 2. Tapada do Ozão, Valença, exemplo de afloramento profusamente gravado com arte atlântica, após aplicação de bicromático.

No Noroeste ocorrem, ainda, outro tipo de manifestações rupestres gravadas. É a designada Arte de Tradição Esquemática que inclui motivos muito esquematizados, incluindo diferentes tipos de reticulados, esteliformes, formas em forma de ferraduras, antropomorfos e raros zoomorfos, sendo, também, considerada como tendo várias fases e ampla diacronia (Figura 3). Data-se da Pré-história Recente, desde o Neolítico à Idade do Bronze, ou seja, entre o 50/40 e o 2 o milénios a. C. (Cardoso, 2015; Cardoso e Bettencourt 2015) ou entre a Idade do Bronze até à Idade Média (Baptista, 1984, 1986).

Há ainda outras manifestações rupestres gravadas, interessantes como recurso, e que se excluem destes dois estilos ou a ele se associam (Cardoso, 2015) como as que representam diversos tipos de podomorfos, datáveis de entre a Idade do Bronze e épocas históricas, consoante as suas características.

Todas estas expressões gravadas em afloramentos rochosos, por vezes de grande impressividade (o que constituiu mais um atrativo), por vezes discretos, representam parte do mundo simbólico das comunidades agrícolas e pastoris do passado, podendo interpretar-se como lugares cerimoniais, simultaneamente celebrativos e integrativos. Aí materializar-se-iam cosmogonias e concepções do mundo que valorizariam os espíritos do meio físico, das plantas e dos animais, entre outros, numa lógica do animismo primitivo. 
Este tipo de percepção do mundo, apesar de ter sido combatida após a implantação do cristianismo na Península Ibérica (entre os séculos III e IV), conforme se verifica pela análise do livro De Correctione Rusticorum de S. Martinho de Dume, Braga, datado do século VI, e pela Constituição do Bispado de Lamego, do século XVI, (Braga, 1885), por exemplo, persistiu até à atualidade nesta área da Península Ibérica. Tal verifica-se, na memória popular, na toponímia e em ritos onde são notórios os resquícios de cultos animistas relacionados com afloramentos, determinados tipos de rochas, bosques, fontes ou com o oceano atlântico, manifestações que a igreja católica tentou cristianizar, reinventando-lhe os sentidos.

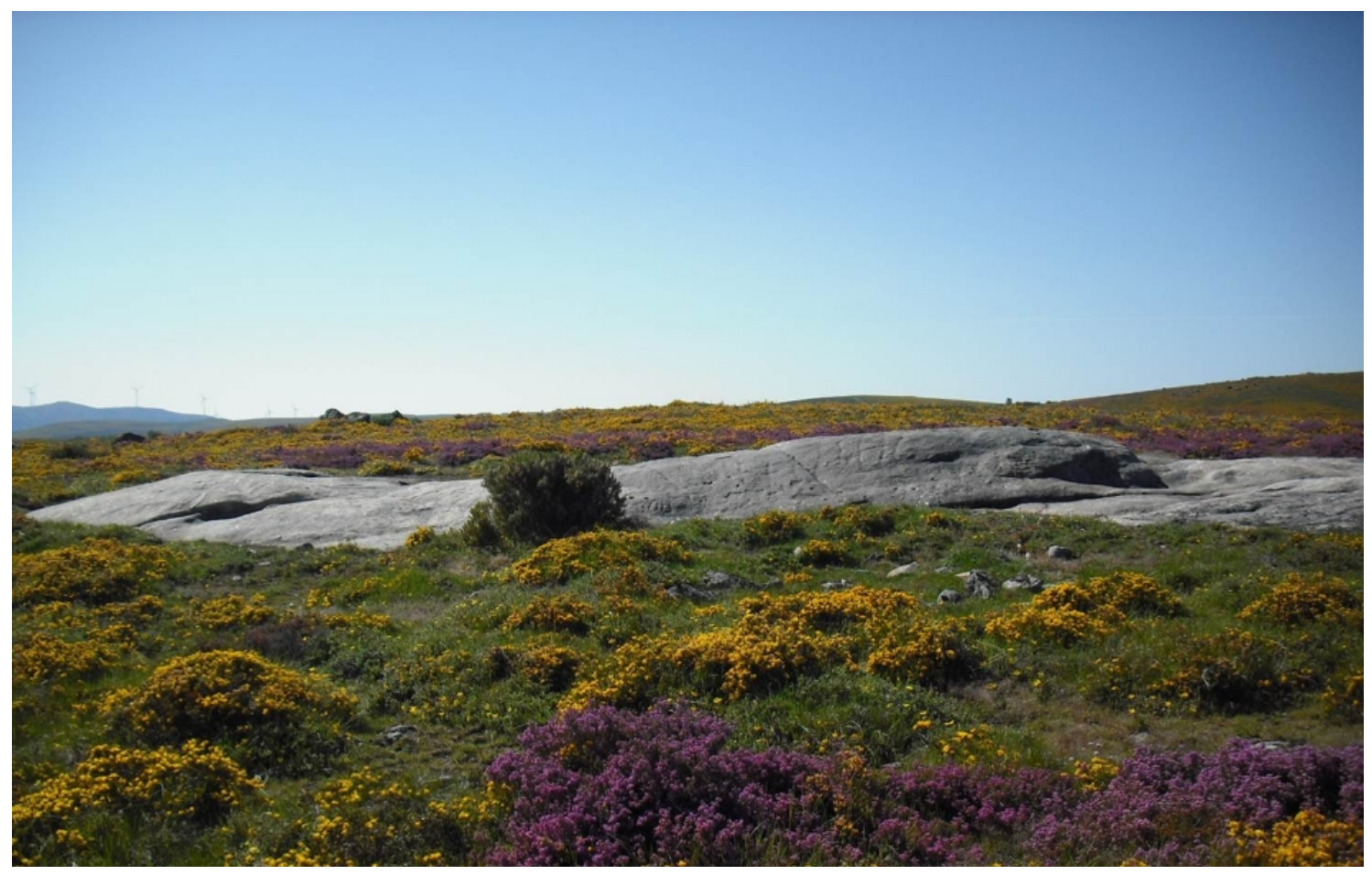

Figura 3. Afloramento profusamente gravado com arte esquemática do Fieiral 2, Planalto de Castro Laboreiro, Melgaço (seg. Bettencourt e Rodrigues, 2013).

Além do incalculável valor científico e das múltiplas narrativas que suscita, a arte rupestre interagiu na paisagem do passado, sendo, portanto, um elemento com valor identitário; além disso, continuou a interagir na paisagem ao longo do tempo tendo, muitas vezes, perdurado na memória imaterial das populações locais e sido alvo de reinterpretações na lógica do cristianismo, o que gera imagem e identidade; apresenta, também, valor económico, porque os projetos de investigação e valorização destes espaços geram oportunidades de negócios e convertem-se em lugares de emprego e de atratividade; apresenta, ainda, valor social, pois o desenvolvimento de um projeto de valorização destes lugares cria laços de identificação com o passado e a melhor compreensão do espaço ocupado, ao mesmo tempo que poderá contribuir para melhorar a qualidade de vida da população, em termos sociais e culturais. Ou seja, trata-se de um projeto sustentável que respeita as três dimensões de sustentabilidade em turismo preconizadas por Perret e Teyssansier (2001) e que são a preservação do(s) recurso(s), o desenvolvimento local e a já designada ética - retorno/partilha, onde o crescimento e o desenvolvimento económico e a qualidade ambiental são compatíveis, onde se preservam os recursos materiais e imateriais para o futuro e onde se utilizará os locais de arte rupestre de 
forma limitada (pois nem todos são passíveis de valorização turística) não comprometendo o seu uso futuro.

Pela sua diversidade temática e cronológica e pelos discursos de inter-relação com o passado que poderá permitir, este recurso arqueológico, não raro localizado em meio rural e em áreas de interesse paisagístico, se dotado de infraestruturas, equipamentos, serviços e experiências, poderá vir a constituir um produto de turismo arqueológico e cultural de grande atratividade.

Se tivermos em conta que os sítios arqueológicos devem ser vistos, por parte dos administradores locais, como recursos endógenos do território que devem ser explorados, de modo a permitir um desenvolvimento económico e social dessa região tal como defende Carbone (2006), então, a transformação de alguns conjuntos rupestres em produto turístico cultural, mediante a criação de uma Rota da Arte Rupestre do Noroeste, é pertinente. De destacar que a existência de gravuras rupestres em afloramentos ou locais com particularidades litológicas e geomorfológicas interessantes poderá potenciar a articulação deste produto turístico cultural com o geoturismo.

Este projeto está igualmente de acordo com os segmentos de mercado destacados como mais importantes até 2020, previstos pela Organização Mundial do Turismo (OMT, 2000) e com os interesses nacionais para o desenvolvimento do sector turístico, de acordo com a aposta no sector do touring cultural, nomeadamente para a Região Porto e Norte de Portugal, preconizada pelo Plano Estratégico Nacional - PENT. Horizonte 2013-2015 (2012) e pelo Turismo de Portugal 2015.

\section{A ROTA DE ARTE RUPESTRE DO NORESTE: PLANEAMENTO}

Tendo em conta o preconizado pela OCDE (1980) e como bem sintetizou Ferreira (2009) para que um projeto se concretize dentro das perspetivas de sustentabilidade é necessário a intervenção de três agentes principais do sector turístico a saber: o visitante; o produtor e/ou o vendedor direto do serviço turístico e a Administração Pública - o produtor indireto de uma parte significativa dos serviços oferecidos aos visitantes.

A necessidade de concretização destas três dimensões no contexto do desenvolvimento do turismo local implica que o projeto seja planeado de acordo com os princípios do planeamento em turismo: 1) estudo prévio; 2) análises SWOT; 3) análise dos estudos de mercado, isto é, de interesse pelo produto; 4) identificação das políticas de desenvolvimento local; 5) inventariação dos recursos, dos produtos, das infraestruturas e dos equipamentos existentes na área ou capacidade para os criar; 6) definição das áreas a incluir no projeto e da sua possível articulação com outros produtos já existentes ou com recursos a desenvolver em termos turísticos; 7) definição da capacidade de carga.

Apesar deste projeto estar ainda a ser desenhado já foram desenvolvidas algumas etapas.

No âmbito do estudo prévio foi realizado o inventário da arte rupestre, segundo perspectivas arqueológicas (que compreende a descrição geomorfológica e litológica dos afloramentos) e antropológicas, através de trabalho de campo e da sua consequente 
informatização. Deste trabalho resultou a identificação dos recursos a valorizar, o estudo aprofundado de alguns locais selecionados pela sua importância científica e patrimonial e a sua publicação científica. De notar que, segundo Hodder e Hutson (2003), entre outros autores, os vestígios arqueológicos são mudos, difíceis de interpretar e pertencentes a um passado desconhecida, pelo que cabe ao arqueólogo o seu estudo e a produção de discursos científicos e de divulgação. Se os primeiros permitem o avanço do conhecimento, os segundos terão que ser capazes de os tornar inteligíveis e, simultaneamente, atrativos visto que se direcionam para o público em geral.

Posteriormente, foram realizadas várias análises SWOT para diferentes áreas de implantação do projeto que funcionaram como ferramenta para aferir das potencialidades turísticas deste tipo de recurso, assim como uma análise SWOT mais genérica que resume os resultados das áreas mais prometedoras.

Com base em toda a informação obtida foram projetados diferentes percursos pedestres, que poderão vir a integrar esta rota se se comprovar a sua viabilidade e interesse por parte das entidades gestoras do território e do público.

No âmbito da análise dos estudos de mercado, isto é, de interesse pelo produto, está em curso uma dissertação de mestrado ${ }^{1}$ que, entre outros temas relacionados com o turismo arqueológico, procurará auscultar o interesse do público pela valorização da arte rupestre existente no Monte de S. Romão, onde se localiza, também, o povoado da Idade do Ferro e da Romanização, conhecido por Citânia de Briteiros, em Guimarães.

Seguem-se alguns dos resultados obtidos até à presente data no decurso deste projeto.

\subsection{Estudo prévio: inventariação dos recursos e identificação dos recursos a valorizar}

A inventariação dos recursos foi iniciada em 2013 por uma vasta equipa que, através de pesquisa documental e de trabalho de campo, reuniu um conjunto significativo de informação, em parte disponibilizada online, através de um website denominado Corpus Virtual de Arte Rupestre do Noroeste Português - CVARN (www.cvarn.org), em outubro de 2014.

Aí foram inventariados e descritos cerca de 600 sítios com gravuras rupestres, alguns deles com mais do que um afloramento gravado (Figura 4). Cabe, ainda, dizer que o CVARN é uma ferramenta em contínua atualização, pelo que atualmente, em trabalho de campo, já se registaram mais de uma centena de novos sítios, embora não atualizados na base de dados. Durante este tipo de trabalho, sempre que possível, foi inventariado o património "intangível" (como lendas, crenças, superstições) ligado a estes recursos.

\footnotetext{
${ }^{1}$ - Helder Carvalho, Perceção dos visitantes e dos agentes locais sobre a Citânia de Briteiros (Guimarães, Norte de
} 


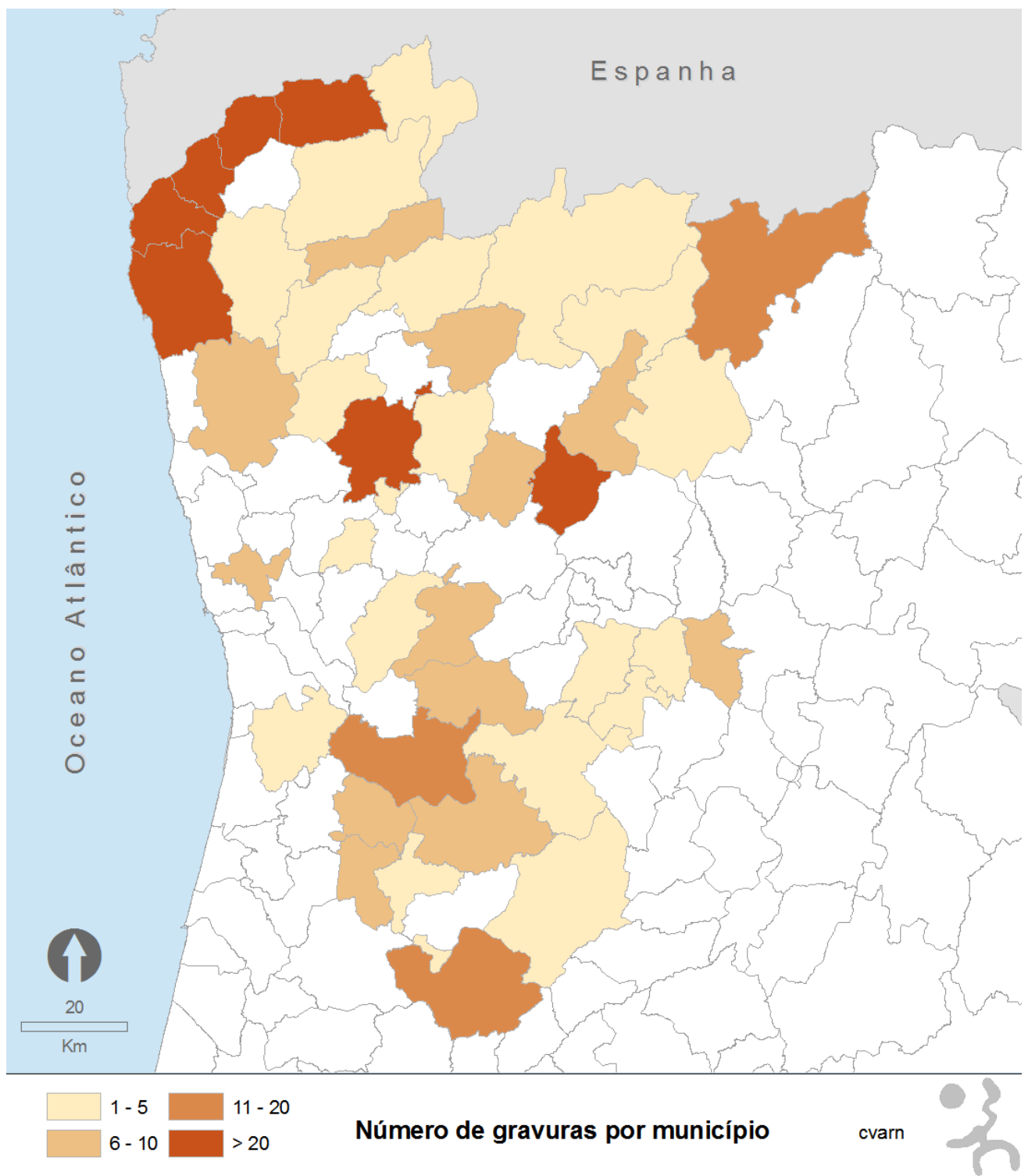

Figura 4. Número de gravuras por concelho inventariadas até 2014, no Noroeste de Portugal, segundo o CVARN.

Com base neste acervo informativo foram identificados os conjuntos ou afloramentos com gravuras rupestres com potencial turístico (tendo em conta as suas condições de conservação, a diversidade de motivos, as particularidades litológicas da superfície rochosa, as geoformas, as acessibilidades e a sua envolvente paisagística). Se alguns destes sítios arqueológicos já tinham sido alvo de publicação científica, como é o caso da Chã da Sobreira, em

Monção (Marques, 1986); do Monte da Laje, Valença (Silva e Cunha, 1986); da Senhora da Encarnação, em Vila Nova de Cerveira (Correia e Recarey, 1988); da Breia, em Viana do Castelo (Bettencourt, 2013a); do anfiteatro do Gião, em Arcos de Valdevez (Baptista 1980, 1981a; Alves, 2013); da Bouça do Colado (Baptista, 1981b; Alves, 2013) (Figura 5) e da Chã da Rapada, ambos em Ponte da Barca (Martins, 2006; Alves, 2011; Bettencourt, 2013b); da Laje dos Sinais, Barcelos 
(Cardoso, 2015); do Penedo dos Sinais, Guimarães (Valdez e Oliveira, 2005/2006) e da restante arte do Monte de S. Romão e de Sabroso, em Guimarães (Cardoso, 2015); do Penedo do Matrimónio, em Montalegre (Bettencourt et al., 2004); de Campelo, em Mondim de Basto (Dinis, 2011); de Lamelas/Eiras, em Ribeira de Pena (Martins, 1981; Abreu, 2012; Gomes, 2014); do Forno dos Mouros, em Sever do Vouga (Alves, 2003), outros foram estudados ou reestudados no âmbito deste projeto.

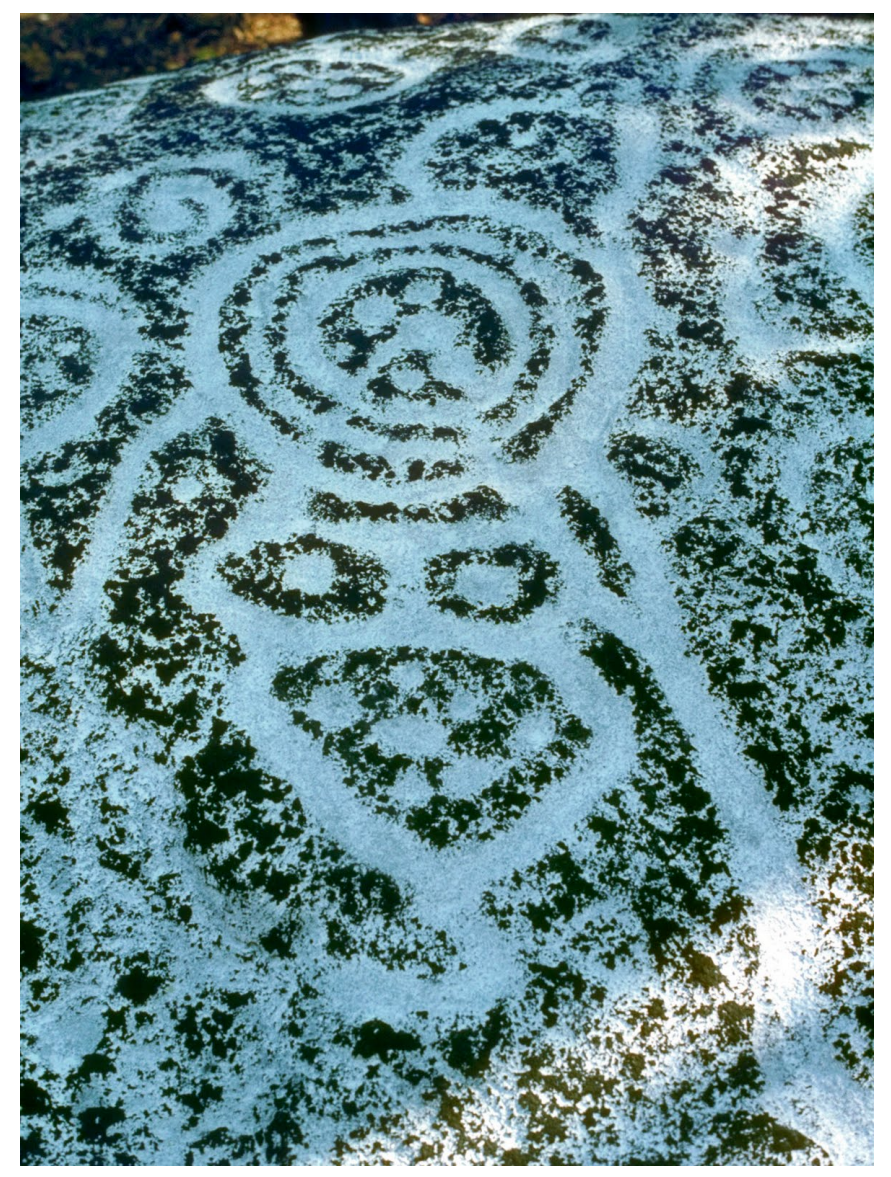

Figura 5. Motivo central do Penedo do Encanto ou das Sete Cabeças, na Bouça do Colado, Ponte da Barca, após aplicação do bicromático (seg. Baptista, 1986).

Tal implicou a sua limpeza, levantamento gráfico, fotográfico e fotogramétrico, estando muito deste trabalho em fase de publicação. Referimo-nos, por exemplo, a Fornelos (Bettencourt et al., no prelo) e a Sinadora, em Carreço; a Chão do Cano e Santo Adrião, em Caminha; à Quinta de Paranho, em Barcelos (Sampaio e Bettencourt, no prelo); à arte rupestre do Monte de S. Gonçalo, em Barcelos (Bettencourt et al. 2016), e ao Penedo de S. Gonçalo, em Felgueiras (Moreira, 2016; Moreira et al., 2016) (Figura 6). 

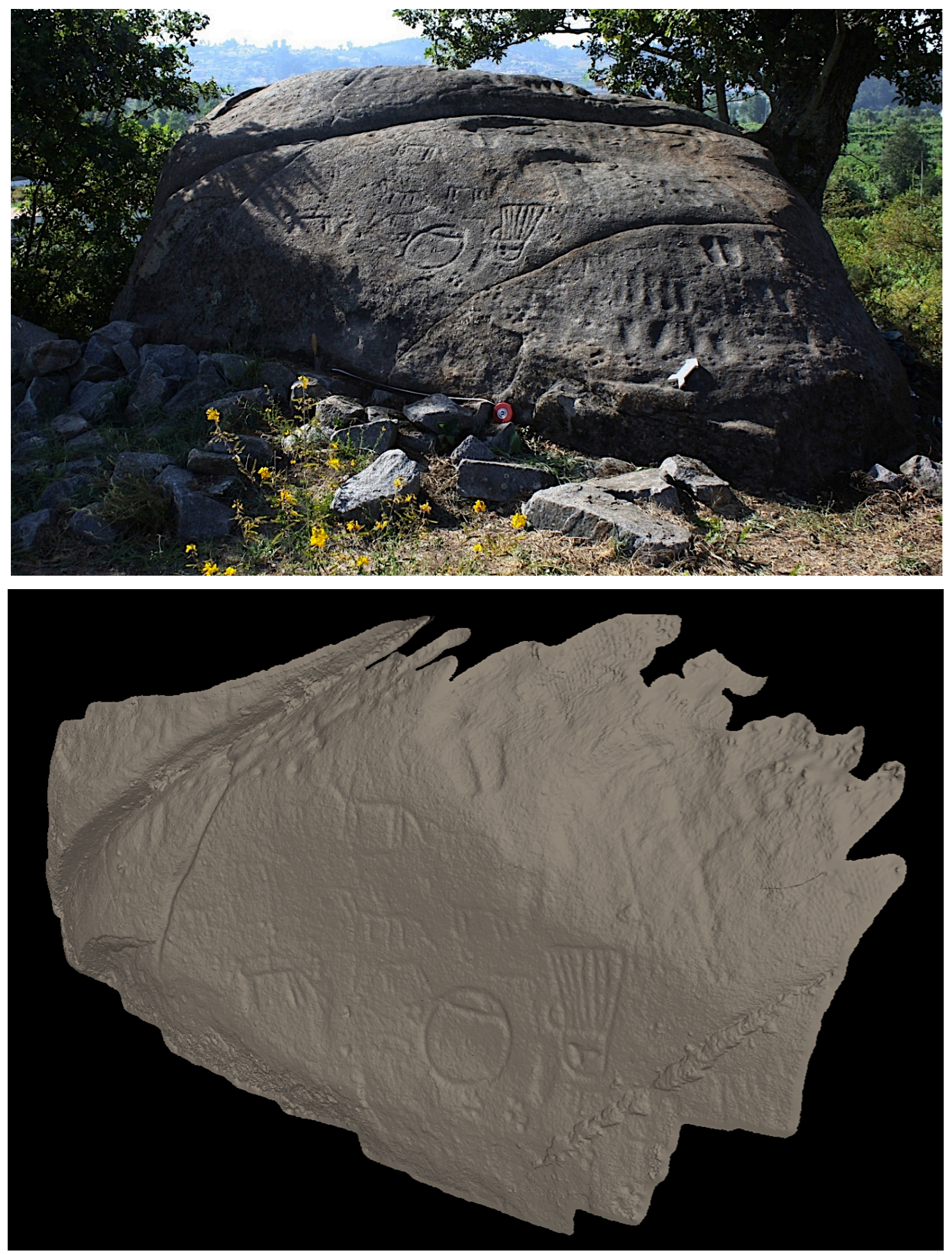

Figura 6. Limpeza do afloramento gravado de S. Gonçalo, em Felgueiras (em cima) e tratamento fotogramétrico de um dos seus painéis (seg. Moreira, 2016 e Moreira et al., 2016) (em baixo). 


\subsection{Análise SWOT}

A análise SWOT sobre a arte rupestre dos vales do Minho e do Lima e dos concelhos de Barcelos e de Guimarães, áreas geográficas com grande concentração de recursos, permitiu perceber as suas potencialidades turísticas. Os seus resultados foram sintetizados na Tabela 1.

Tabela 1: Análise SWOT ao recurso arte rupestre para os casos dos vales dos rios Lima e Minho e dos concelhos de Barcelos e Guimarães

\begin{tabular}{|c|c|}
\hline Pontos Fortes & Pontos Fracos \\
\hline $\begin{array}{l}\text { - Grande número de gravuras passíveis de } \\
\text { visitação; } \\
\text {. Gravuras distribuídas por vários concelhos; } \\
\text {. Diversidade de estilos e de motivos gravados; } \\
\text {. Gravuras existentes em meio rural; } \\
\text {. Existência de gravuras em afloramentos com } \\
\text { interesse litológico ou geoformal ; } \\
\text {. Existência de gravuras em locais com património } \\
\text { geológico destacável; } \\
\text {. Enquadramento paisagístico das gravuras } \\
\text { selecionadas; } \\
\text {. Existência de estudos cientificamente validados } \\
\text { de alguns locais com gravuras rupestres; } \\
\text {. Musealização de alguns locais gravados. }\end{array}$ & $\begin{array}{l}\text { Vulnerabilidade aos agentes naturais } \\
\text { (derrocadas, incêndios, etc.); } \\
\text {. Vulnerabilidade ao vandalismo; } \\
\text {. Visibilidade reduzida de alguma gravuras } \\
\text { durante algumas horas do dia; } \\
\text {. Falta de sinalética adequada para percursos já } \\
\text { existentes; } \\
\text {. Escassez de Centros Interpretativos com } \\
\text { informação validada e atrativa. } \\
\text {. Falta de uma política adequada de divulgação. }\end{array}$ \\
\hline Oportunidades & Ameaças \\
\hline $\begin{array}{l}\text {. Possibilidade de articular algumas gravuras com } \\
\text { lendas e tradições locais; } \\
\text {. Existência de produtos de turismo cultural, } \\
\text { paisagístico e desportivo já consolidados no } \\
\text { território com possibilidade de se articularem com } \\
\text { este novo produto; } \\
\text {. Facilidade dos meios de comunicação para as } \\
\text { sedes dos concelhos e freguesias próximos das } \\
\text { gravuras; } \\
\text {. Proximidade de cidades com grande fluxo } \\
\text { turístico como Guimarães, Barcelos e Viana do } \\
\text { Castelo; } \\
\text {. Proximidade do aeroporto Sá Carneiro e do cais } \\
\text { de cruzeiros do Porto de Leixões; } \\
\text {. Contexto paisagístico de qualidade (com especial } \\
\text { destaque para as gravuras inseridas no Parque } \\
\text { Natural da Peneda-Gerês); } \\
\text {. Clima relativamente favorável que permite o } \\
\text { usufruto deste recurso durante, pelo menos a } \\
\text { primavera, verão e outono; } \\
\text {. Unidades hoteleiras e restauração existentes em } \\
\text { todos os concelhos; } \\
\text {-Aposta do Turismo de Porto e Norte de Portugal } \\
\text { no Touring Cultural. }\end{array}$ & $\begin{array}{l}\text { Sazonalidade do turista; } \\
\text {. Falta de manutenção dos acessos aos locais } \\
\text { gravados já musealizados; } \\
\text {. Falta de informação das autarquias e dos } \\
\text { restantes stakeholders sobre o valor da arte } \\
\text { rupestre; } \\
\text { - Falta de sensibilidade para a sua valorização; } \\
\text {. Dificuldades no uso de transportes públicos até } \\
\text { aos inícios dos percursos. }\end{array}$ \\
\hline
\end{tabular}


Em relação aos pontos fortes destaque, desde logo, para o robusto número de gravuras passíveis de visitação, para a sua diversidade e, sobretudo, para a sua distribuição por vários concelhos. Este último aspeto é crucial, na medida em que permite uma distribuição mais equilibrada de oferta e, por conseguinte, de visitantes, contrariando a sua canalização apenas para determinadas regiões, com impacto direto no desenvolvimento socioeconómico mais amplo e não tão localizado. Além do seu enquadramento de excelência, permitindo uma acentuada proximidade à natureza e, em muitos casos, a modos de vida rurais e tradicionais, destaque para a possibilidade de articulação do recurso arte rupestre com outros produtos turísticos da área, como a gastronomia e vinhos, o artesanato, ou outros diferentes tipos de património, seja ele cultural ou natural, como é o caso de património geológico do litoral de Viana do Castelo, reconhecido como de interesse turístico (Carvalhido et al., 2009).

Quanto às oportunidades destaque, desde logo, para a existência real e física de inúmeros produtos turísticos culturais, paisagísticos e desportivos já bem implementados na região que se podem articular com este subproduto. A par disto refira-se, também, a existência de unidades hoteleiras e de restauração em todos os concelhos, capazes de receber os visitantes. A facilidade de comunicação entre os diferentes municípios e as freguesias, em especial por intermédio dos respetivos organismos com competências de gestão (Juntas de Freguesia e Câmaras Municipais), e a proximidade de cidades com grande fluxo turístico, como Guimarães, Braga e Viana do Castelo, do Aeroporto Sá Carneiro e do cais de cruzeiros do Porto de Leixões, permitem alavancar ainda mais o potencial deste recurso. Pela sua qualidade indiscutível, deverá ser sublinhado o contexto paisagístico de excelência proporcionado pelo Parque Natural da Peneda-Gerês no interior do qual existem conjuntos de arte rupestre passíveis de visitação.

Em relação aos pontos fracos, a par da vulnerabilidade das gravuras aos agentes naturais (principalmente aos incêndios e ao vandalismo), outro dos principais problemas prende-se com a sua observação durante determinadas horas do dia.

Consoante o tipo de granito gravado os incêndios podem ser muito destrutivos fazendo estalar a superfície dos afloramentos o que leva à destruição das gravuras. Em relação ao vandalismo, que se vai tornando cada vez menor, à medida que o índice cultural da população aumenta, será ainda necessário desenvolver manuais e campanhas de boas práticas. O problema da visualização das gravuras só se coloca em alguns casos. Nesses, a programação das visitas para certos momentos específicos, como o início do dia, o final da tarde ou durante a noite, será a melhor estratégia. De resto, as visitas noturnas são experiências de valor acrescido, não só pela melhor observação dos motivos gravados que permitem como, também, por toda a envolvência e ambiência com o sítio que fomentam. A melhora dos caminhos de acesso, a falta de sinalética e de Centros de Acolhimento ou Interpretativos, com informação validade e atrativa, e a falta de uma política adequada de divulgação, são, de todos os pontos fracos, os que mais dificilmente poderão ser resolvidos, sem intervenção direta dos agentes de desenvolvimento local e regional.

No que respeita a ameaças, a falta de manutenção dos acessos poderá ser contrariada pela ação mais contundente das autarquias locais. Um maior empenho da comunidade científica em sistematizar e estudar estes locais poderia, mais do que tornar estes locais conhecidos nos meios académicos, servir de ponte para a sensibilização dos municípios e do público em geral para a sua valorização e proteção. Em especial, também, para colmatar a falta de informação das 
autarquias e dos stakeholders sobre o real valor da arte rupestre. A questão das dificuldades em conjugar transportes públicos até ao inícios de alguns dos percursos será algo que, com a boa vontade das partes envolvidas, poderá igualmente ser minimizado.

Como se pode verificar pela análise efetuada, os pontos fortes e as oportunidades são mais expressivos do que os pontos fracos e as ameaças, sendo muitos dos pontos fracos, diagnosticados, passíveis de serem melhorados. Assim, de um modo geral, cremos que é possível a valorização turística de muitos destes recursos, mediante a criação de diversos subprodutos no âmbito desta rota, concretamente, de diferentes percursos.

\subsection{Possíveis percursos pedestres}

Em termos académicos foram, ainda, projetados diferentes percursos a materializar. Contudo, a sua concretização implica a convergência de sinergias e de apoios financeiros.

Alguns destes percursos integraram dissertações de mestrado (Sá, 2015) e têm sido divulgados em Congressos Internacionais (Bettencourt e Rodrigues, 2015: Bettencourt et al., 2015; Sá e Bettencourt, 2015; Cardoso e Bettencourt, 2015; Sampaio e Brochado, 2015). Na sua base conjugam sítios com arte rupestre com outros tipos de patrimónios, nomeadamente o cultural e natural (Figura 7).

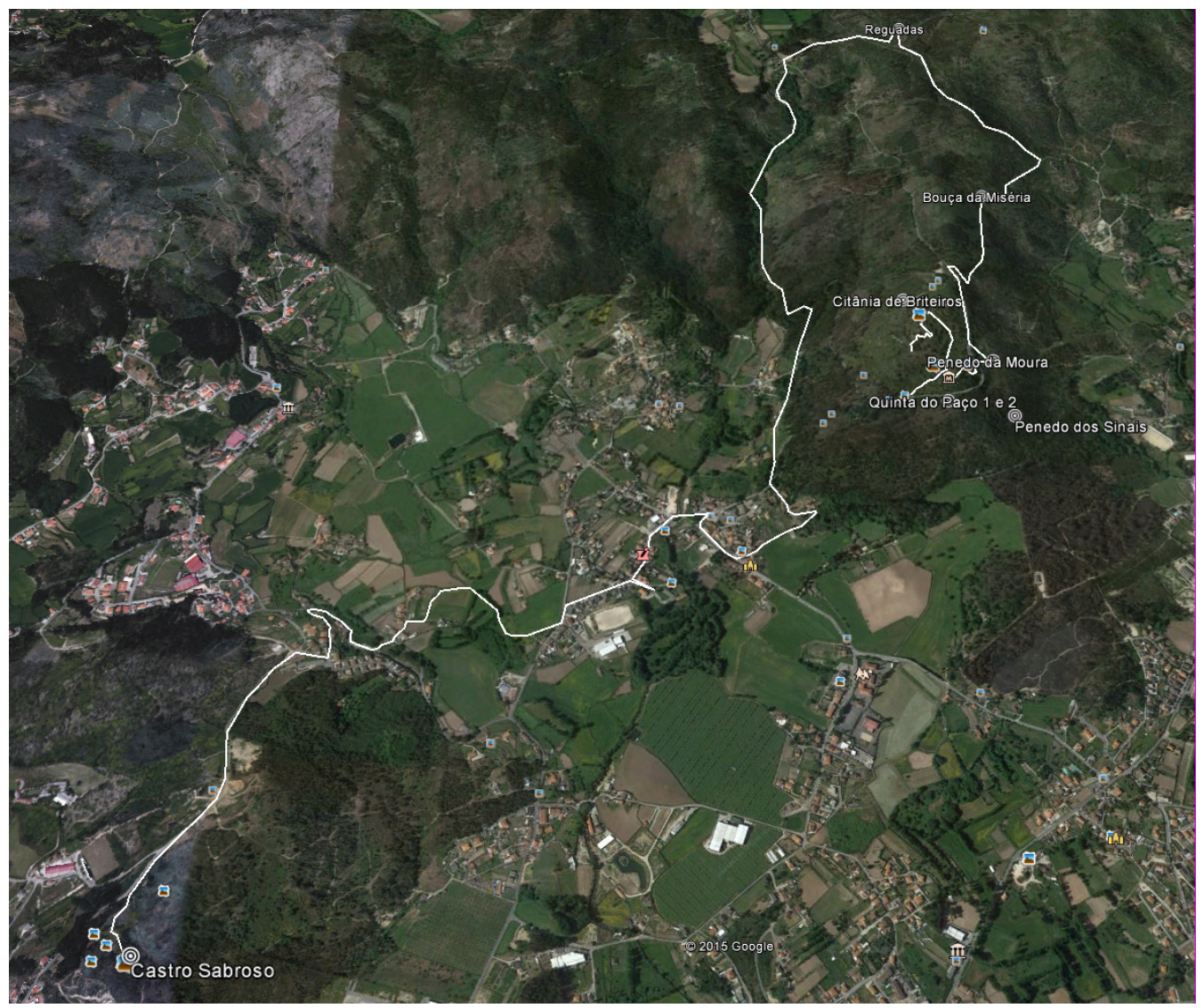

Figura 7. Percurso piloto valorizando a arte rupestre entre os Monte de S. Romão e o Monte do Coto de Sabroso, no concelho de Guimarães, em articulação com outro património histórico

(seg. Cardoso e Bettencourt, 2015). 


\section{A ROTA DE ARTE RUPESTRE DO NORESTE: QUE FUTURO?}

Este trabalho foi realizado no âmbito do Laboratório de Paisagens, Património e Território - Lab2PT da Universidade do Minho e do Departamento de Turismo e Marketing do Instituto Politécnico do Cávado e do Ave, em Barcelos, com o apoio de alguns municípios durante a fase de inventariação (sendo exemplo os de Viana do Castelo, Caminha, Vila Nova de Cerveira, Barcelos e Penafiel).

Neste momento o projeto está em fase de estabelecimento de parcerias e captação de financiamento para a implementação das condições de valorização, divulgação e promoção do recurso arte rupestre, que permitirão a sua transformação num produto turístico-cultural de excelência no Noroeste de Portugal.

A Rota de Arte Rupestre do Noroeste é um projeto que, pelas suas características e pelos outputs que a sua implementação criará, se integra na política nacional de salvaguarda, proteção e valorização do património cultural, no âmbito da Lei 107/2001 de 8 de Setembro e, manifesta os princípios consagrados na Carta Internacional de Turismo Cultural (ICOMOS, 1999). Está em total sintonia com os objetivos do Portugal 2020 e da ESTRATÉGIA REGIONAL DE ESPECIALIZAÇÃO INTELIGENTE - RIS3, que reconhece como ponto forte da Região Norte o "Vasto património histórico-cultural, arquitectónico, natural e paisagístico". Este documento de referência, a RIS3, no domínio de especialização VIII - Capital Simbólico, Tecnologias e Serviços do Turismo, identifica o património cultural como um recurso e um ativo da Região Norte, sendo que o racional de especialização, para o domínio VIII se centra na "Valorização de recursos culturais e intensivos em território, aproveitando as capacidades científicas e tecnológicas, nomeadamente nas áreas da gestão, marketing e TIC, e a oferta turística relevante, promovendo percursos e itinerâncias como forma de aproveitamento das principais infraestruturas de entrada de visitantes" (CCDR-N - Comissão de Coordenação e Desenvolvimento Regional do Norte, 2014).

O estabelecimento de parcerias passa pela cooperação de diversas instituições e stakeholders e a captação de financiamento poderá passar pelo Programa Operacional Norte2020, especificamente pelo Eixo Prioritário 4 - Qualidade Ambiental, Objetivo Temático 6 Preservar e proteger o ambiente e promover a utilização eficiente dos recursos, Prioridade de Investimento 6.3 - Conservação, proteção, promoção e desenvolvimento do património natural e cultural, Objetivo Específico 4.1.1 - Promover a valorização da excelência do património cultural e natural no contexto de estratégias regionais distintivas de desenvolvimento turístico (CCDR-N Comissão de Coordenação e Desenvolvimento Regional do Norte, 2014a).

\section{AGRADECIMENTOS}

Este trabalho foi desenvolvido no âmbito do projeto Rota da Arte Rupestre do Noroeste. Um projeto de Turismo Cultural (RAR Project Lab2PTOct2014), inscrito e suportado pelo Lab2PT/Universidade do Minho. As figuras 1 e 4 foram realizadas por Emílio Abad-Vidal, a quem agradecemos. Agradecemos aos revisores as críticas construtivas. 


\section{REFERÊNCIAS}

ABREU, M. (2012). Rock-Art in Portugal: History, Methodology and Traditions. Vila Real: Universidade de Trás-os-Montes e Alto Douro (Tese de Doutoramento).

ALVES, L. B. (2003). The movement of signs: Post-glacial rock art in northwetern lberia. Universidade de Reading.

ALVES, L. B. (2011). Génio e talento do passado. A arte gravada do Penedo do Encanto e da Chã da Rapada. Adere/Arqueohoje, Lda.

ALVES, L. B. (2013). Gravuras rupestres da Bouça do Colado / Penedo do Encanto, Lindoso, Ponte da Barca. In A.M.S. Bettencourt A Pré-História do Noroeste Português/The Prehistory of the North-western Portugal, Territórios da Pré-História em Portugal, vol. 2. Braga/Tomar: ARKEOS/CITCEM, 201-206.

BAPTISTA, A. M. (1980). Introdução ao Estudo da Pré-História do Noroeste Peninsular. As gravuras do Gião. Minia 3 (4), 80-100.

BAPTISTA, A. M. (1981a). A arte do Gião, Arqueologia, 3: 56-66.

BAPTISTA, A. M. (1981b). O complexo de arte rupestre da Bouça do Colado (Parada, Lindoso). Notícia preliminar. Giesta, 1: 6-16.

BATISTA, A. M. (1984). Arte rupestre do norte de Portugal: uma perspectiva. Portugália, 34: 7188.

BATISTA, A. M. (1986). Arte rupestre pós-glaciária. Esquematismo e abstração. In. J. Alarcão (coord.). História da Arte em Portugal. Do Paleolítico à Arte Visigótica. Vol 1. Lisboa: Alfa, 31-55.

BETTENCOURT, A. M. S. (2013a). Gravuras rupestres da Breia, Cardielos, Viana do Castelo / The rock engravings of Breia, Cardielos, Viana do Castelo. In: A.M.S. Bettencourt, A Pré-História do Noroeste Português / The Prehistory of the North-western Portugal, Territórios da Pré-História em Portugal, vol. 2. Braga/Tomar: ARKEOS/CITCEM, 207-215.

BETTENCOURT, A. M. S. (2013b). Gravuras rupestres da Chã da Rapada, Britelo, Ponte da Barca, In: A.M.S. Bettencourt, A Pré-História do Noroeste Português / The Prehistory of the North-western Portugal, Territórios da Pré-História em Portugal, vol. 2. Braga/Tomar: ARKEOS/CITCEM, 162-168.

BETTENCOURT, A. M. S.; RODRIGUES, A. (2013) . As gravuras rupestres do Fieiral, Castro Laboreiro, Melgaço". In: A.M.S. Bettencourt, A Pré-História do Noroeste Português / The Prehistory of the North-western Portugal, Territórios da Pré-História em Portugal, vol. 2. Braga/Tomar: ARKEOS/CITCEM,132-139.

BETTENCOURT, A. M. S.; RODRIGUES, A. (2015). Arte rupestre da bacia do Minho (NW de Portugal): recurso turístico ao serviço do desenvolvimento regional. Arqueologia, Património e Turismo no Vale do Minho, Monção: Câmara Municipal de Monção/Projecto Arqueológico de Longos Vales, 7. 
BETTENCOURT, A. M. S.; SANCHES, M. J.; DINIS, A.; CRUZ, C. S. (2004). The rock engravings of Penedo do Matrimónio, in Campo de Caparinho, Vilar de Perdizes, Montalegre (Northern Portugal). Journal of Iberian Archaeology, 6:61-82.

BETTENCOURT, A. M. S.; RODRIGUES, A.; SAMPAIO, H. A. (2015). Thinking a Touristic Route of Rock Art to the Northwest of Portugal, In IV International Congress on Tourism - CIT 2015. Guimarães: ESG/IPCA, 66-68.

BETTENCOURT, A.M.S.; BROCHADO, C.; FERREIRA, G.; MAGALHÃES, M.; SAMPAIO, H.A. (2016). "Rock art of S. Goncalo Hill, Barcelos (NW Portugal) and the construction of a structural place in the prehistoric landscape", poster apresentado no Simpósio Images in Stones, Braga, 30 de novembro de 2016, disponível em https://uminho.academia.edu/AnaBettencourt/Posters.

BETTENCOURT, A. M. S. ; ALVES, M.I.C.; SIMÕES, P.P.; SILVA, I.S. (no prelo). To where do the horses run? A dialogue between signs and matter in the rock carvings of Fornelos, Viana do Castelo, North-Western Portugal. In A.M.S. Bettencourt, M. Santos Estevez, D. Cardoso, H.A. Sampaio (eds.), Recorded Places, Experienced Places. The Holocene Rock Art of the Iberian Atlantic Northwest, BAR, Archeopress, Oxford.

BRAGA, T. (1885). O Povo Português nos seus Costumes, Crenças e Tradições. Coimbra: Imprensa da Universidade.

CARBONE, F. (2006). Turismo, Património e Sustentabilidade. Modelos de Gestão para Sítios Arqueológicos. Aveiro: Universidade de Aveiro.

CARVALHIDO, R., PEREIRA, D.; BRILHA, J. (2009). Inventariação do património geomorfológico do litoral do concelho de Viana do Castelo, Publicações da Associação Portuguesa de Geomorfólogos, 6, 299-304.

CARDOSO, D. (2015). A Arte Atlântica do Monte de S. Romão / Guimarães) no Contexto da Arte Rupestre Pós-paleolítica da Bacia do Ave - Noroeste Português, Vila Real: Universidade de Trásos-Montes e Alto Douro (Tese de Doutoramento - policopiada).

CARDOSO, D.; BETTENCOURT, A.M.S. (2015). The "Rock Art Route" of Northwest of Portugal: Guimarães county, In IV International Congress on Tourism - CIT 2015. Guimarães: ESG/IPCA, 110111.

CCDR-N - Comissão de Coordenação e Desenvolvimento Regional do Norte (2014). Estratégia Regional de Especialização Inteligente [acedido a 20 de agosto de 2016 emhttps://www.portugal2020.pt/Portal2020/Media/Default/Docs/EstrategiasEInteligente/EREI\% 20Norte.pdf].

CCDR-N - Comissão de Coordenação e Desenvolvimento Regional do Norte (2014a). Estratégia Regional de Especialização Inteligente. [acedido a 15 de julho de 2016 em http://www.norte2020.pt/documentos/documentos-fundamentais].

CORREIA, V.; RECAREY, M. A. (1988). As gravuras da Serra da Gávea, Vila Nova de Cerveira, Actas do Colóquio em Homenagem a Manuel Boaventura. Vol. 2, Esposende: Câmara Municipal, 93111. 
DINIS, A. (2011). O santuário rupestre de Campelo, Mondim de Basto (Norte de Portugal). Oppidum 5: 11-26.

DUVAL, M. E.; SMITH B. (2013). Rock art tourism in the Ukhahlamba/Drakensberg world heritage site: obstacles to the development of sustainable tourism, Journal of Sustainable Tourism, 21 (1): 134-153.

FERREIRA, L. (2009). Planeamento Estratégico de Destinos Turísticos, Atas do 15o Congresso da APDR, Cidade da Praia, Cabo Verde, 1509-1537.

GOMES, N. A. C. (2014). Estudo do Sítio com Gravuras Rupestres de Lamelas (S. Salvador) - Ribeira de Pena). Porto: Universidade do Porto (dissertação de Mestrado).

HODDER, I.; HUTSON, S. (2003). Reading the past: current approaches to interpretation in Archeology, ( $3^{\text {rd }}$ edition). Cambridge: Cambridge University Press.

ICOMOS (1999). Carta Internacional do Turismo Cultural. 12a Assembleia Geral no México, Centro de Documentação da UNESCO - ICOMOS.

MAIA, S. V.; BAPTISTA, M. M. (2011). As rotas como estratégia turística: percepção de benefícios e obstáculos na constituição de rotas museológicas na região de Aveiro. In J. J. Águas; P. Ribeiro; F. P. Santos (Eds.), Book of Proceeding of International Conference on Tourism \& Management Studies, Vol. I, Aveiro: Universidade de Aveiro, 672-682.

MAIA, S. V.; MARTINS, U.; BAPTISTA, M. M. (2013). Turismo cultural no contexto urbano: rotas museológicas - os casos de Aveiro e ílhavo (Portugal). Revista Brasileira de Pesquisa em Turismo, 7 (2): 192-208.

MARQUES, J. A. M. (1986). As gravuras da Chã da Sobreira e a arte rupestre no concelho de Monção. Revista de Ciências Históricas, 1: 11-30.

MARTINS, A. (2006). Gravuras rupestre do Noroeste Peninsular: a Chã da Rapada. Revista Portuguesa de Arqueologia 9 (1), 47-70.

MARTINS, M. J. C. (1981). O Santuário Rupestre de Lamelas (Ribeira de Pena). Tarouca: C. M. Ribeira de Pena.

MOREIRA, J. (2016). O Penedo de S. Gonçalo (Varziela, Felgueiras), Encontro Internacional de Novos Investigadores de Arqueoloxía e Ciencias da Antiguidade. Abstracts-EINIACA2016. Santiago de Compostela: Arcian, 12-13.

MOREIRA, J.; BETTENCOURT, A.M.S; SANTOS-ESTÉVEZ, M. (2016). The Penedo de S. Gonçalo, Felgueiras, NW of Portugal. The long life of an engraved place, poster apresentado no Simpósio Images in Stones, Braga, 30 de novembro de 2016, disponível em https://uminho.academia.edu/AnaBettencourt/Posters.

OCDE (1980). L'impact du tourisme sur l'environnement. Paris. Versión española de F. Pichot y J. R. Rapado: La fiscalidad y el medio ambiente. Políticas complementarias. Madrid: OCDE/ Ediciones Mundi-Prensa.

ORGANIZAÇÃO MUNDIAL DO TURISMO, (2000). Tendências de evolução aos níveis mundial, europeu e nacional. Porto, Associação Empresarial de Portugal. 
PERRET, J. e TEYSSANSIER, J. (2001). Quelques propositions pour piloter le tourisme durable dans les territoires et les entreprises. Seminário de Investigação em Turismo, Escola de Turismo do Estoril.

PLANO ESTRATÉGICO NACIONAL - PENT. HORIZONTE 2013-2015 (2012). Lisboa: Gabinete do Ministro da Economia e do Emprego. Disponível em (ww.turismodeportugal.pt/Português/turismodeportugal/publicacoes/Documents/PENT 2012.pdf)

(S/A) (2009). Rock Art Sites on the Unesco World Heritage List. Bibliography. França: UNESCO ICOMOS Documentation Centre.

SÁ, S. 2015. Turismo Arqueológico: um Projeto de Valorização da Arte Rupestre do Vale do Lima. Braga: Universidade do Minho (Dissertação de Mestrado - policopiada).

SÁ, S.; BETTENCOURT, A.M.S. (2015). Thinking a Touristic Route of Rock Art to the Northwest of Portugal: the case study of Lima basin, In IV International Congress on Tourism - CIT 2015. Guimarães: ESG/IPCA, 69-70.

SAMPAIO, H. A.; BROCHADO, C. (2015). Arte rupestre e Turismo no concelho de Barcelos (Portugal): proposta de percursos temáticos no âmbito da "Rota de Arte Rupestre do Noroeste", In IV International Congress on Tourism - CIT 2015. Guimarães: ESG/IPCA, 65.

SAMPAIO, H. A.; BETTENCOURT, A.M.S. (no prelo). Novos sítios de arte rupestre na bacia do rio Cávado, Noroeste de Portugal, The Art of Prehistoric Societies, Proceedings of IV Metting of Doctoral and Posdoctoral Reachersers, novembro de 2015. Techne. Mação: Instituto Terra e Memória.

SANTOS-ESTÉVEZ, M. (2012). Unha visión diacrónica da arte atlántica dentro dun novo marco cronolóxico. In M. J. Sanches (coord.), Atas da Iㅁ Mesa Redonda. Artes Rupestres da Pré-História e da Proto-História: Paradigmas e Metodologias de Registo. Trabalhos de Arqueologia, 54. Lisboa: DGPC, 219-238

SILVA, E.J.L.; CUNHA, A.L. (1986). As gravuras rupestres do Monte da Laje (Valença). Livro de Homenagem a Jean Roche. Lisboa: Instituto Nacional de Investigação Cientifica: 490-505

TURISMO DE PORTUGAL (2015). Turismo 2020 cinco princípios para uma ambição tornar Portugal o destino turístico mais ágil e dinâmico da Europa (http://www.turismodeportugal.pt/PORTUGU\%C3\%8AS/TURISMODEPORTUGAL/DESTAQUE/Doc uments/turismo-2020-cinco-principios-para-uma-ambicao.pdf).

VALDEZ, J.; OLIVEIRA, L. (2005/2006). A arte rupestre da Citânia de Briteiros. O Penedo dos Sinais, um caso Atlântico. Revista de Guimarães 115/116: 51-89. 